\title{
CREEP PROPERTIES OF BIOFILLER- AND FIRE RETARDANT-FILLED POLYPROPYLENE COMPOSITES
}

\author{
KOKI MATSUMOTO*, KENICHI TAKEMURA, HITOSHI TAKAGI, TATSUYA TANAKA \& \\ MASAHIRO SASADA \\ Research and Development Center for Advanced Composite Materials (RDCCM), Doshisha University, Japan.
}

\begin{abstract}
Biofillers, lignocellulosic and cellulosic fillers have the potential to significantly improve the mechanical properties of polypropylene (PP) and reduce its carbon footprint by reducing the amount of petroleum-derived polymer used. In addition, the realization of fire retardancy of biofiller-filled PP composites is an important key topic to enhance their applications; ammonium polyphosphate (APP) is an effective fire retardant (FR). In this study, to ensure the reliability of biofiller- and FR-filled PP composites, the creep properties were investigated in terms of the filler and FR content and filler type. In particular, the influence of APP addition into polymer composites on the creep properties has not been studied thoroughly. Two biofillers, wood flour (WF) and cellulose filler (CeF), with similar particle sizes and aspect ratios were used in this study. The creep test was conducted at a temperature of 80 ${ }^{\circ} \mathrm{C}$ in an accelerated test. Furthermore, the creep strain curves were modelled by the Burgers model of the viscoelastic constitutive equation to analyse the creep deformation behaviour. The incorporation of biofillers into the PP matrix significantly decreased the creep strain and improved the creep-rupture life with increasing filler content. Moreover, the creep-rupture life was longer for WF-filled PP composites than for CeF-filled PP composites. On the other hand, we found that incorporation of FR increased the creep rate at steady state and decreased the creep-rupture life of biofiller-filled PP composites, although the instantaneous creep strain decreased.
\end{abstract}

Keywords: ammonium polyphosphate, cellulose filler, creep property, polypropylene, wood flour.

\section{INTRODUCTION}

From the perspective of environmental loading and the circular economy, the use of petroleum-derived polymers should be reduced [1], and the plastic industries must consider sustainability. Thus, biopolymers, which are made from renewable resources, have received great attention as alternatives to petroleum-derived polymers. However, polyolefins, in particular polyethylene (PE) and polypropylene (PP), account for more than $50 \%$ of the produced polymers [2]. PE and PP are used for diverse applications owing to their good mechanical properties, chemical resistance and low cost. Therefore, many ideas have been proposed to reduce the environmental impact of polyolefins. One of the strategies for reducing the consumption of polyolefins is incorporating biofillers, such as lignocellulosic and cellulosic materials, into polyolefin matrices. By adding up to approximately $70 \mathrm{wt} \%$ of relatively inexpensive biofillers to polyolefins, the amount of polymer is decreased, which means that the carbon footprint is reduced [1]. Moreover, wood flour (WF)-filled plastic composites (WPCs) are recyclable, increasing filler content improves the mechanical properties [3], and its use reduces the material costs.

* ORCID: http://orcid.org/0000-0002-4220-7304 
Generally, WPCs are used as a replacement for solid wood for decking, fencing and siding, and their market is growing every year. Since extruded profile WPC is used for outdoor applications, the mechanical properties of WPC are affected by temperature, ultraviolet (UV) radiation and moisture absorption/desorption cycles [4]. Therefore, it is important to investigate the mechanical properties of WPC, especially the creep properties, under various conditions for long-term use. Takemura [5] revealed the influence of water absorption on the bending creep properties of jute-reinforced PP composites. Water absorption for 70 days increased the strain at the primary creep stage and the creep rate at steady state (secondary creep stage). Oever and Molenveld [4] revealed that a higher temperature increased the bending creep strain of WPC profiles. Additionally, the mechanical properties of WPC are strongly dependent on the interfacial adhesion between the polymer and the filler. Thus, to restrict creep deformation, the addition of maleic anhydride-grafted polypropylene (MAPP) [6-8], the chemical treatment of fillers by using sodium hydroxide $(\mathrm{NaOH})$ [9], the use of a silane cupping agent $[9,10]$ and the acetylation of wood [11] are effective solutions. Interestingly, the incorporation of only $1 \mathrm{wt} \%$ organoclay into the WF-filled PP composite shows better creep resistance.

Normally, a long-term creep test requires quite a long time to investigate the time-dependent deformation of a sample. For the prediction of the long-term creep deformation of WPCs, the time-temperature superposition (TTS) technique can be used to accelerate the creep test; the TTS technique can be applied to WPCs [9, 11, 13-15]. By conducting a short-term creep test at different temperatures and determining shift factors by using the Williams-Landel-Ferry (WLF) or the Arrhenius equation, a master curve of creep against the reference temperature can be obtained. Furthermore, for the prediction of creep strain against time, the creep curve can be modelled by using the Burgers model $[8,9,13,14]$.

Determining the fire retardancy of WPCs is also important for spreading their application. For the fire retardant (FR), ammonium polyphosphate (APP) is an effective additive for achieving excellent fire retardancy (V-0 rating) according to the UL-94 [16]. However, the addition of APP deteriorates the mechanical properties of WPCs since APP is an inorganic polar material, and the compatibility between APP and nonpolar polymer PP is poor [17-21]. In our previous research, we revealed that the amount of APP could be reduced to $10 \mathrm{wt} \%$ by the addition of $50 \mathrm{wt} \% \mathrm{WF}$ [16] and cellulose powder [22] to achieve a V-0 rating. To ensure the reliability of these materials, the creep properties of biofiller-filled PP, especially the influence of FR addition on the creep properties, should be investigated. However, the effect of FR addition on the creep properties has not been thoroughly investigated.

In this study, two kinds of biofillers, WF and cellulose filler $(\mathrm{CeF})$, were prepared. These fillers were melt-mixed with PP and APP through a twin-screw extruder. The creep test of injection-moulded specimens was conducted at a relatively high temperature of $80{ }^{\circ} \mathrm{C}$ for the accelerated test. The objective of this study was to reveal the effects of the filler type and FR and filler content on the creep properties, namely, the viscoelastic deformation and creep-rupture life.

\section{THEORETICAL BACKGROUND}

Creep mainly occurs above the glass transition temperature $\left(T_{\mathrm{g}}\right)$ of a polymer, and creep deformation is viscoelastic deformation. Generally, the creep strain curve is represented as shown in Fig. 1a, and the curve can be modelled by the Burgers model of the viscoelastic constitutive equation $[8,9,13,14]$. Creep strain is divided into three types of deformation 
up to the secondary creep stage: (I) instantaneous strain $\varepsilon_{0}$ by elastic deformation, (II) creep strain $\Sigma \varepsilon i$ at the primary stage (transient creep) by viscoelastic deformation and (III) creep strain $\varepsilon_{\mathrm{n}}$ at the secondary stage (steady state) by viscous deformation. The total creep strain $\varepsilon$ total up to the secondary creep stage is expressed by eqn (1):

$$
\varepsilon_{\text {total }}=\varepsilon_{0}+\sum_{i=1}^{n-1} \varepsilon_{i}+\varepsilon_{n}
$$

The Burgers model is a combination of the Maxwell model and the Kelvin-Voigt model and consists of elastic elements (springs) and viscous elements (dashpots) [13], as shown in Fig. 1b. The total strain of the Burgers model is given by eqn (2):

$$
\begin{gathered}
\varepsilon_{\text {total }}=\frac{\sigma}{E_{0}}+\sum_{i=1}^{n-1} \frac{\sigma}{E_{i}}\left[1-\exp \left(-\frac{t}{\tau_{i}}\right)\right]+\frac{\sigma}{\eta_{n}} t \\
\tau_{i}=\frac{\eta_{i}}{E_{i}}
\end{gathered}
$$

where $\sigma$ is the applied stress, $t$ is the elapsed time, $E_{0}$ is the elastic modulus at instantaneous deformation, $E i$ is the elastic modulus of the spring and $\eta i$ is the viscosity of the dashpot of the $i$ th element. As expressed in eqn (3), the ratio $\eta i / E i$ is the retardation time $\tau i$, the required time for extension of the spring while the dashpot retards the deformation response up to the equilibrium length. The retardation time has a spectrum, and thus, the creep strain at the primary stage is expressed by a series of Kelvin-Voigt models, as shown in Fig. 1b. The Burgers model can be adopted for use in the linear viscoelastic (LVE) region (details are presented in section 4.1). In this study, the creep strain curves were fitted by Burgers model with six elements $(n=3)$ through nonlinear least-squares regression for estimation of parameters.

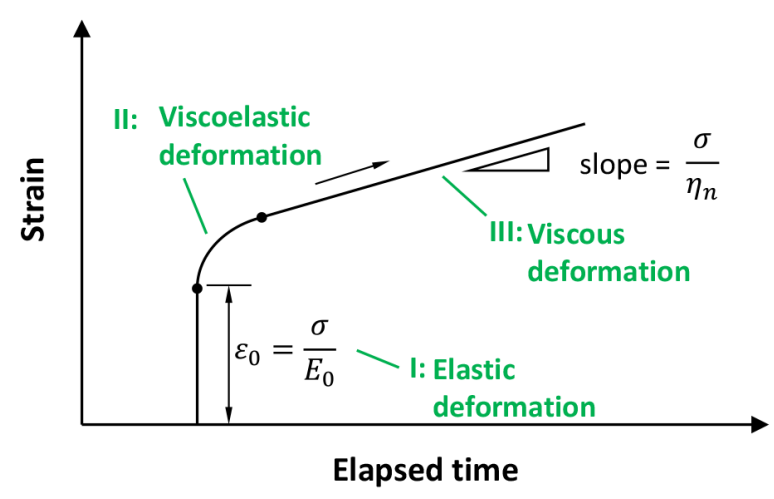

(a)

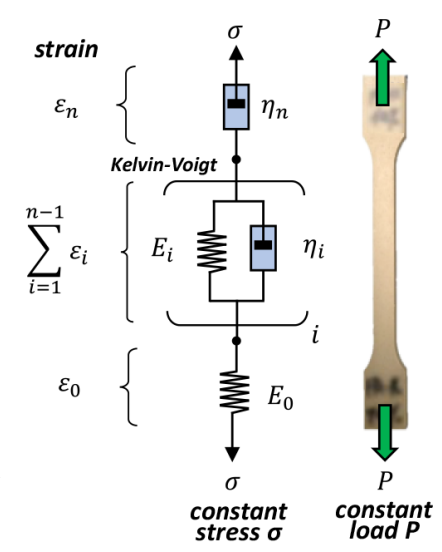

(b)

Figure 1: (a) Typical creep curve (strain versus elapsed time) and (b) Burgers model consisting of the Maxwell model and the Kelvin-Voigt model. 


\section{EXPERIMENTAL PROCEDURES}

\subsection{Materials and fabrication of composites}

The polymer matrix was a PP block copolymer (VMD81M, SunAllomer Ltd., Japan), which had a melt flow rate (MFR) of $100 \mathrm{~g} / 10 \mathrm{~min}$. For the biofillers, WF and CeF were used. The particle diameters of the biofillers were measured through laser diffraction, and the median particle diameters of the $\mathrm{WF}$ and $\mathrm{CeF}$ were $35.6 \mu \mathrm{m}$ and $31.4 \mu \mathrm{m}$, respectively. The aspect ratio of both particle types was approximately 1.8. Scanning electron microscopy (SEM) images of the WF and the $\mathrm{CeF}$ are shown in Fig. 2a and b. From the SEM images, the filler shapes of the WF and $\mathrm{CeF}$ appear to be plate-like and fibre-like, respectively. To improve the compatibility between the filler and the polymer matrix, MAPP (Kayabrid® 002PP, Nouryon Japan K.K., Japan) was used. For the FR, APP (Taien K, Taihei Chemical Industrial Co., Ltd., Japan) was used. An SEM image of APP is shown in Fig. 2c. The filler shape of APP appears to be spherical. The particle size of APP has a wide distribution, and the maximum particle size is approximately $50 \mu \mathrm{m}$.

For the fabrication process, all materials (PP, WF or CeF, MAPP and APP) were compounded through a twin-screw extruder, and compounded granules were obtained. In the next step, dumbbell-shaped tensile specimens (type 1A, ISO527) were fabricated through injection moulding by using compounded granules. The formulations of the fabricated composites are listed in Table 1. The MAPP was added as $4 \%$ of the filler contents.

\subsection{Tensile creep test at $80^{\circ} \mathrm{C}$}

The tensile creep test was conducted by using a tensile creep apparatus (CREEP TESTER L100ER, Toyo Seiki Seisaku-sho, Ltd., Japan). For the accelerated test, an environmental temperature of $80^{\circ} \mathrm{C}$ was selected. The $T_{\mathrm{g}}$ of PP is $0-4{ }^{\circ} \mathrm{C}$, and its crystalline mobility begins in the range of $50-100{ }^{\circ} \mathrm{C}$ [23]. The moulded dumbbell specimens were set in the grip and equilibrated at $80{ }^{\circ} \mathrm{C}$ for 30 min before the creep test was started. In this study, two modes of creep tests were conducted: (I) Constant-stress mode tests were performed at 5.0 MPa for up to $72 \mathrm{~h}$, and the creep curves were compared. The obtained experimental creep curves were fitted by the Burgers model. (II) Creep-rupture tests were carried out by applying a relatively high stress (e.g. $60 \%, 70 \%$ and $80 \%$ of the tensile strength at $80{ }^{\circ} \mathrm{C}$ ). The objective of the creep-rupture test is to determine the creep-rupture life at the applied stress. Before the tensile creep test was performed, the static tensile test was conducted, and the tensile strengths of all the composites were determined. The fracture morphology was observed by SEM (VE7800 , Keyence Corporation, Japan) at an acceleration voltage of $10 \mathrm{kV}$.

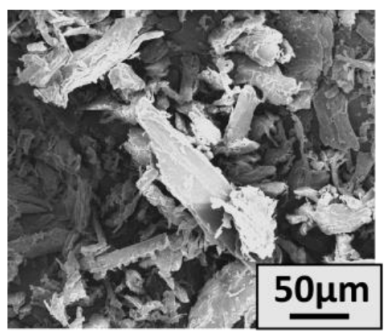

(a)

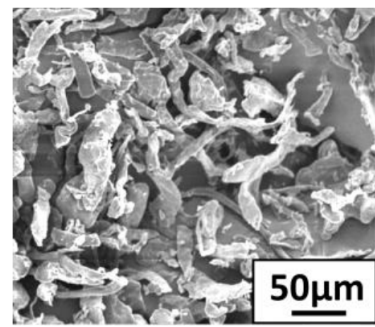

(b)

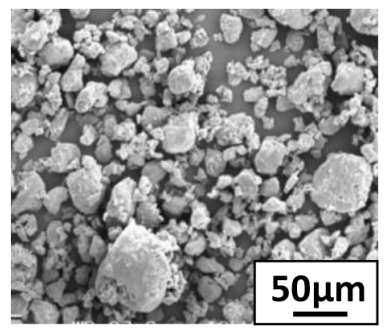

(c)

Figure 2: SEM micrographs: (a) WF, (b) CeF and (c) APP (fire retardant). 
Table 1: The formulations and abbreviations used for the fabricated composites.

\begin{tabular}{lllll}
\hline Abbreviation & $\begin{array}{l}\text { PP } \\
{[\mathbf{w t} \%]}\end{array}$ & $\begin{array}{l}\text { MAPP } \\
{[\mathbf{w t} \%]}\end{array}$ & $\begin{array}{l}\text { WF (CeF) } \\
{[\mathbf{w t} \%]}\end{array}$ & $\begin{array}{l}\text { FR } \\
{[\mathbf{w t} \%]}\end{array}$ \\
\hline PP & 100 & - & - & - \\
WF40 (CeF40) & 58.4 & 1.6 & 40 & - \\
WF45 (CeF45) & 53.2 & 1.8 & 45 & - \\
WF50 (CeF50) & 48.0 & 2.0 & 50 & - \\
WF40FR10 (CeF40FR10) & 48.4 & 1.6 & 40 & 10 \\
WF40FR20 (CeF40FR20) & 38.4 & 1.6 & 40 & 20 \\
WF50FR10 (CeF50FR20) & 38.0 & 2.0 & 50 & 10 \\
WF50FR20 (CeF50FR20) & 28.0 & 2.0 & 50 & 20 \\
\hline
\end{tabular}

\section{RESULTS AND DISCUSSION}

\subsection{Creep strain curves of PP and determination of the LVE region}

The creep strain curves of PP under various applied stresses (i.e. 50\%, 60\%, 70\% and 80\% of the tensile strength) are presented in Fig. 3a. The actual values of the applied stress are also shown. The PP samples fractured at all stress levels. As shown in Fig. 3a, the creep behaviour strongly depends on the magnitude of the applied stress. Thus, creep compliances $J(=\varepsilon(\mathrm{t}) / \sigma)$ were calculated as shown in Fig. 3b. To determine the LVE region, Nuñez et al. [13] conducted creep tests at different stress magnitudes, and the strain at the elapsed time of 30 min was plotted against the applied stress to find the region of linear correlation. Franz et al. [24] determined the LVE region from creep compliance data. If the creep compliance curves at different stress levels fall on the same line, then the LVE region can be determined. As shown in Fig. 3b, except for the creep curve at $80 \%$ of the tensile strength, the strain at the tertiary stage of each creep curve was the same, and the linear correlation (the red solid line)

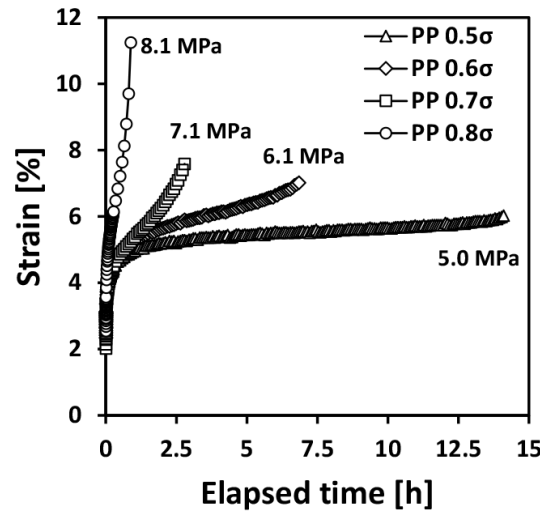

(a)

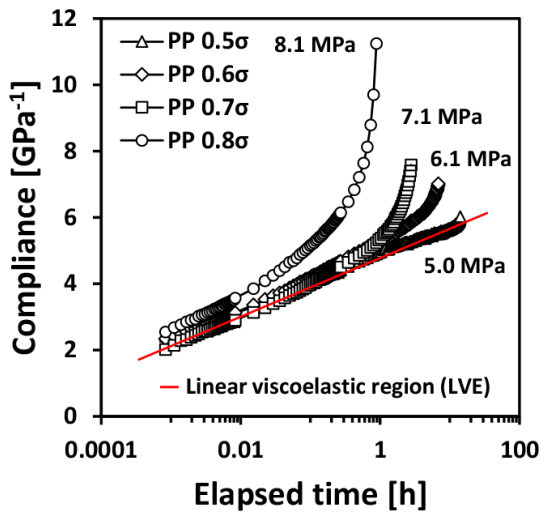

(b)

Figure 3: (a) Creep curves of pure PP under various applied stresses and (b) creep compliance curves of pure PP under various applied stresses. 
could be observed. Thus, creep tests at an applied stress less than 5.0 MPa may contain the LVE region. Therefore, in this study, the creep test was conducted at 5.0 MPa regardless of the composite system, and fitting by the Burgers model was conducted against these experimentally obtained creep curves.

\subsection{Influence of WF and $\mathrm{CeF}$ addition on creep properties}

In this section, the influence of the filler content and filler type on the creep properties without the addition of FR is discussed. The creep curves of WF-filled PP composites and CeF-filled PP composites at an applied stress of 5.0 MPa are displayed in Fig. 4. Please note that WF- or CeF-filled PP composites did not fracture at a stress of 5.0 MPa, although pure PP fractured at this stress. Regardless of the filler type, the creep strain significantly decreased at higher filler contents. Furthermore, the fitting parameters for the Burgers model are listed in Table 2, and the fitted curves are exhibited as solid lines in Fig. 4. The coefficient of determination $\left(R^{2}\right)$ was above 0.98 in all samples, and good correlation was confirmed. Primarily, $E_{0}$ increased with filler loading, which means that the instantaneous strain $\varepsilon_{0}$ decreased. In the transient creep region, the elastic modulus $E i$ and retardation time $\tau i$ also increased dramatically. This indicates that the amount of creep strain in the transient region decreased and required more time to shift to steady-state creep deformation. Moreover, the viscosity $\eta_{n}$ increased with increasing filler content. In other words, the creep rate (the slope of the creep strain curve) decreased with higher filler loading in the steady state. Hence, these results suggest that the reinforcement effect of fillers and the improvement of the adhesion between the filler and PP by MAPP may have contributed to the restriction of creep deformation.

Comparing the WF and $\mathrm{CeF}$, the reduction in creep strain was almost the same. Besides, the creep rate, $1 / \eta_{n}$, of the WF-filled PP composite in the steady state decreased significantly with increasing WF content. However, in the case of the CeF-filled PP composites, the reduction in the creep rate against the filler content was less than that of the WF-filled composites. Thus, WF may have a better reinforcement effect than CeF on the creep property.

Furthermore, the relationship between the applied stress and the rupture time is presented in Fig. 5a. In a short-term creep test (up to $20 \mathrm{~h}$ ), the linear correlation between the applied stress and rupture time was confirmed. The slope of the straight line did not differ between

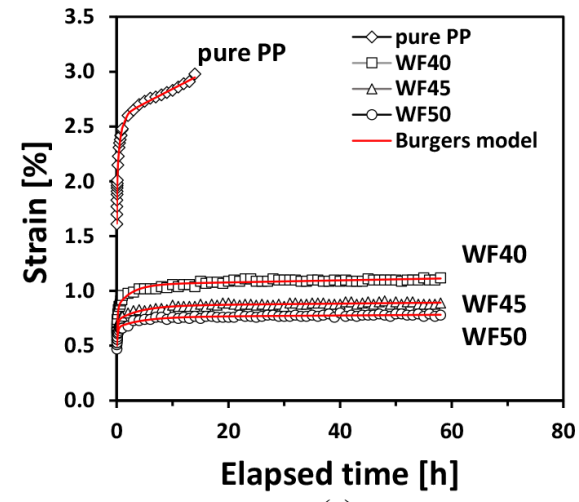

(a)

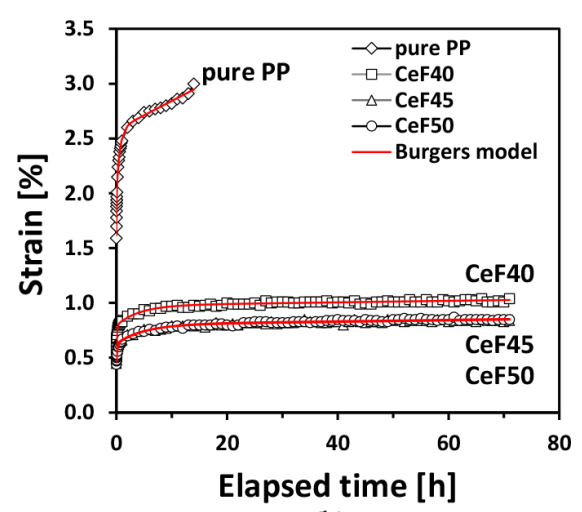

(b)

Figure 4: Creep curves of (a) WF-filled PP composites and (b) CeF-filled PP composites. The creep test was conducted under a constant applied stress of 5.0 MPa. 
Table 2: Fitting parameters of (a) WF-filled PP composites and (b) CeF-filled PP composites by the Burgers model $(n=3)$.

(a)

\begin{tabular}{lllllll}
\hline Abbreviation & $\mathbf{E}_{\mathbf{0}}[\mathbf{G P a}]$ & $\mathbf{E}_{\mathbf{1}}[\mathbf{G P a}]$ & $\boldsymbol{\tau}_{\mathbf{1}}[\mathbf{s}]$ & $\mathbf{E}_{\mathbf{2}}[\mathbf{G P a}]$ & $\boldsymbol{\tau}_{\mathbf{2}}[\mathbf{s}]$ & $\boldsymbol{\eta}_{\mathbf{n}}[\mathbf{P a} \mathbf{s}]$ \\
\hline PP & 0.33 & 1.06 & 177 & 0.84 & 2,215 & $6.88 \times 10^{7}$ \\
WF40 & 0.80 & 2.21 & 603 & 2.41 & 9,549 & $1.92 \times 10^{9}$ \\
WF45 & 0.92 & 2.70 & 623 & 3.68 & 15,012 & $3.87 \times 10^{9}$ \\
WF50 & 1.02 & 2.83 & 639 & 5.27 & 16,091 & $5.03 \times 10^{9}$ \\
\hline
\end{tabular}

(b)

\begin{tabular}{lllllll}
\hline Abbreviation & $\mathbf{E}_{\mathbf{0}}[\mathbf{G P a}]$ & $\mathbf{E}_{\mathbf{1}}[\mathbf{G P a}]$ & $\boldsymbol{\tau}_{\mathbf{1}}[\mathbf{s}]$ & $\mathbf{E}_{\mathbf{2}}[\mathbf{G P a}]$ & $\boldsymbol{\tau}_{\mathbf{2}}[\mathbf{s}]$ & $\boldsymbol{\eta}_{\mathbf{n}}[\mathbf{P a} \cdot \mathbf{s}]$ \\
\hline PP & 0.33 & 1.06 & 177 & 0.84 & 2,215 & $6.88 \times 10^{7}$ \\
CeF40 & 0.86 & 2.33 & 446 & 2.71 & 14,829 & $2.59 \times 10^{9}$ \\
CeF45 & 1.07 & 3.06 & 558 & 2.97 & 17,143 & $2.65 \times 10^{9}$ \\
CeF50 & 1.10 & 2.96 & 691 & 2.72 & 18,616 & $2.76 \times 10^{9}$ \\
\hline
\end{tabular}

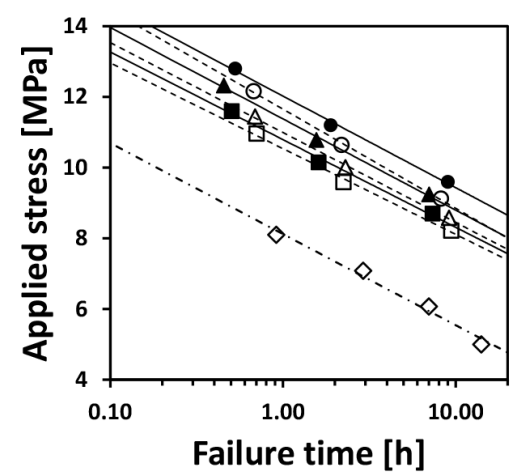

(a)

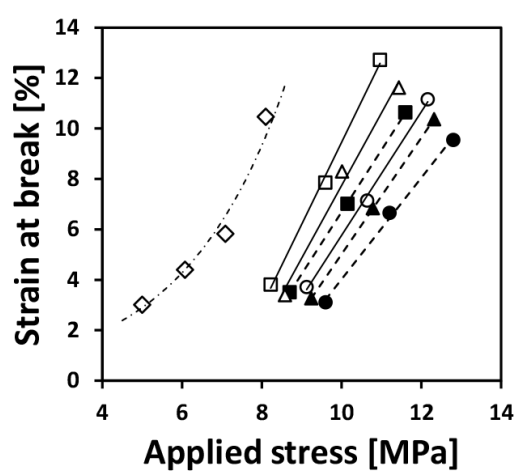

(b) $\diamond$ pure PP

- WF40

$\triangle$ WF45

- WF50

$\square$ CeF40

$\triangle \mathrm{CeF} 45$

O CeF50

Figure 5: (a) Creep-rupture curves of pure PP and PP-based composites and (b) strain at break against the applied stress of pure PP and PP-based composites.

the pure PP and PP-based composites. Besides, the straight lines were shifted upward with increasing filler content regardless of the filler type. This result means that filler addition increases the creep-rupture life. Comparing WF and CeF, the creep life of the CeF-filled PP composites was slightly shorter than that of the WF-filled PP composites. As explained in the previous paragraph, the CeF-filled PP composites exhibited a higher creep rate in the second stage than the WF-filled PP composites. From the literature [25], higher lignin contents improved the mechanical properties of semi-bleached cellulose fibre-reinforced PP composites. In our study, the geometric shape of the filler may not influence the mechanical properties due to the almost identical aspect ratios of WF and CeF. Figure 6 shows the creep fracture surfaces of PP, WF50 and CeF50 under stress of $60 \%$ of the tensile strength. The elongation of PP along the tensile direction was reduced by the addition of biofillers. Furthermore, the pull-out of CeF was observed when WFs were wrapped by PP. Thus, the lignin 

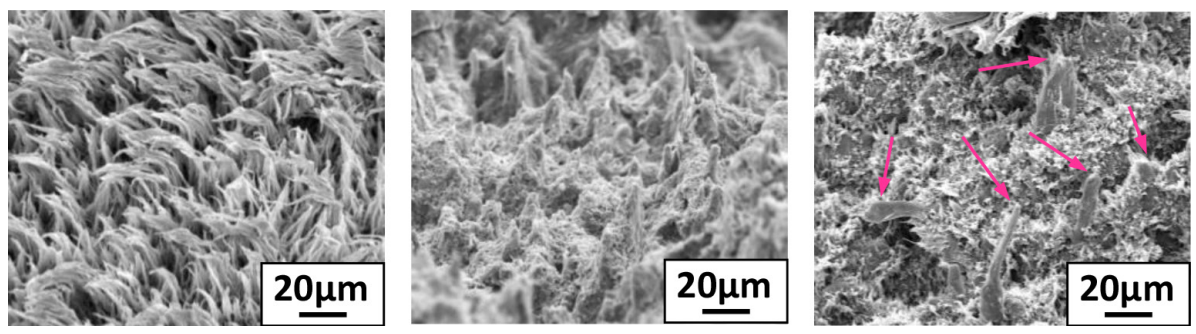

Figure 6: The fracture surfaces under 60\% stress: (a) PP, (b) WF50 and (c) CeF50.

component at the surface of WF might have contributed to improving the compatibility of the WF and the PP matrix. The relationship between the applied stress and fracture strain is depicted in Fig. 5b. The WF-filled PP composites exhibited a lower fracture strain than the CeF-filled PP composites due to hindering the deformation. For these reasons, WF-filled PP composites show better creep properties than CeF-filled PP composites.

\subsection{Influence of FR addition on creep properties}

In this section, the influence of FR addition to the biofiller-filled PP composites on the creep properties is discussed. For example, the creep strain curves of the WF (50 wt \%)-filled PP composites with various FR contents and $\mathrm{CeF}$ (50 wt $\%$ )-filled PP composites with various FR contents are shown in Fig. 7a and b. Furthermore, the fitting parameters are listed in Table 3. As shown in Fig. 7, the creep strain decreased with increasing FR content. The creep deformation behaviour was analysed in detail using the fitting parameters in the Burgers model. Please note that the value of $R^{2}$ was above 0.97 . The value of $E_{0}$ increased with the addition of FR. Thus, FR addition contributed to the decrease in the instantaneous strain $\varepsilon_{0}$. In the transient creep region, the elastic modulus Ei increased with higher FR loading. However, interestingly, the retardation time $\tau i$ decreased with increasing FR content. Furthermore, the viscosity $\eta_{n}$ in steady-state creep also decreased with FR addition. These decreasing tendencies of the retardation time and viscosity are completely different from the case of biofiller

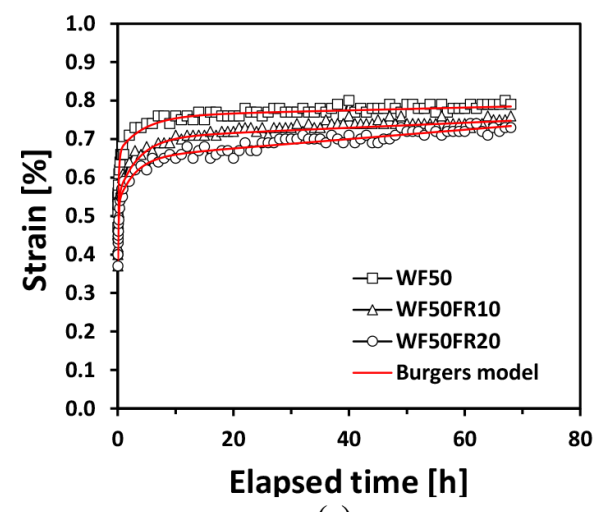

(a)

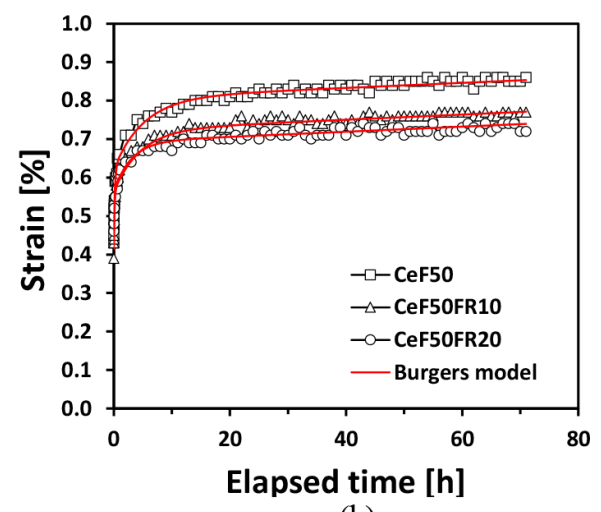

(b)

Figure 7: Creep curves of (a) WF (50 wt\%)-filled PP composites with various FR contents and (b) $\mathrm{CeF}$ (50 wt\%)-filled PP composites with various FR contents. The creep test was conducted under a constant applied stress of 5.0 MPa. 
Table 3: Fitting parameters by the Burgers model ( $n=3$ ) of (a) WF (50 wt $\%$ )-filled PP composites with various FR contents and (b) CeF (50 wt $\%$ )-filled PP composites with various FR contents.

(a)

\begin{tabular}{lllllll}
\hline Abbreviation & $\mathbf{E}_{\mathbf{0}}[\mathbf{G P a}]$ & $\mathbf{E}_{\mathbf{1}}[\mathbf{G P a}]$ & $\boldsymbol{\tau}_{\mathbf{1}}[\mathbf{s}]$ & $\mathbf{E}_{\mathbf{2}}[\mathbf{G P a}]$ & $\boldsymbol{\tau}_{\mathbf{2}}[\mathbf{s}]$ & $\boldsymbol{\eta}_{\mathbf{n}}[\mathbf{P a} . \mathbf{s}]$ \\
\hline WF50 & 1.02 & 2.83 & 639 & 5.27 & 16,091 & $5.03 \times 10^{9}$ \\
WF50FR10 & 1.32 & 2.88 & 506 & 3.33 & 12,848 & $2.76 \times 10^{9}$ \\
WF50FR20 & 1.34 & 3.12 & 426 & 4.21 & 10,625 & $1.48 \times 10^{9}$ \\
\hline
\end{tabular}

(b)

\begin{tabular}{lllllll}
\hline Abbreviation & $\mathbf{E}_{\mathbf{0}}[\mathbf{G P a}]$ & $\mathbf{E}_{\mathbf{1}}[\mathbf{G P a}]$ & $\boldsymbol{\tau}_{\mathbf{1}}[\mathbf{s}]$ & $\mathbf{E}_{\mathbf{2}}[\mathbf{G P a}]$ & $\boldsymbol{\tau}_{\mathbf{2}}[\mathbf{s}]$ & $\boldsymbol{\eta}_{\mathbf{n}}[\mathbf{P a} \cdot \mathbf{s}]$ \\
\hline CeF50 & 1.10 & 2.96 & 691 & 2.72 & 18,616 & $2.76 \times 10^{9}$ \\
CeF50FR10 & 1.25 & 3.10 & 421 & 3.10 & 16,233 & $2.69 \times 10^{9}$ \\
CeF50FR20 & 1.23 & 3.14 & 201 & 3.91 & 10,752 & $2.73 \times 10^{9}$ \\
\hline
\end{tabular}

addition. Even though FR addition reduces the instantaneous creep strain and the strain in the transient region, the decrease in retardation time in the transient region and viscosity in the steady-state region means that the resistance to deformation decreases and that the creep rate increases with the addition of FR. Therefore, during long-term use, FR addition may produce a higher creep strain than biofiller-filled PP composites without FR. According to the literature [17-21], APP generally deteriorates the static mechanical properties of composites due to the poor adhesion between APP (inorganic material) and PP (organic material). Thus, the increase in the creep rate in the steady state may be attributed to weaker adhesion between APP and PP.

Furthermore, the influence of the FR content on the failure time of biofiller-filled PP composites is presented in Fig. 8. In addition, the strain at break of biofiller-filled PP composites with various FR contents against the applied stress is summarized in Fig. 9. As shown in Fig. 8, the straight line shifts down with increasing FR content regardless of the filler type and content. For instance, the creep-rupture life is similar for biofiller (50 wt $\%)$-filled PP

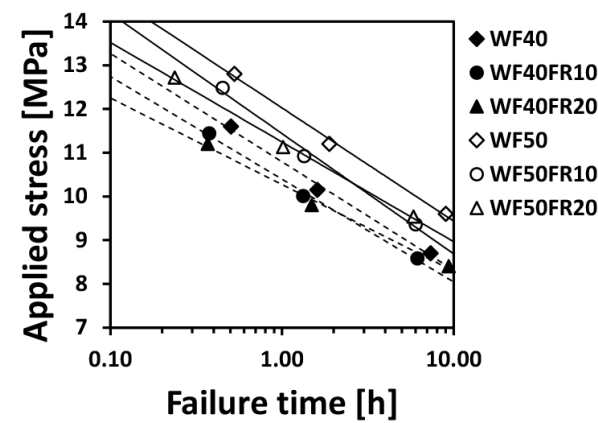

(a)

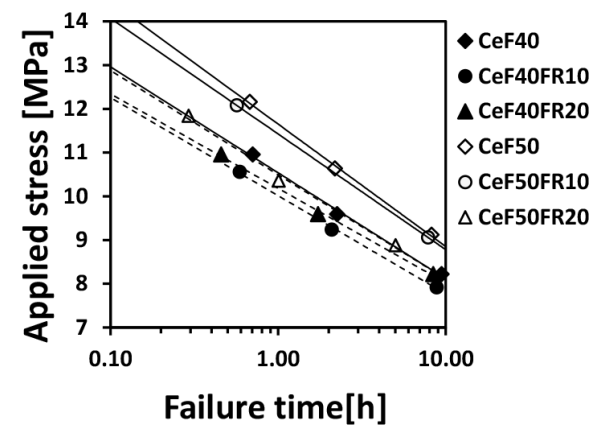

(b)

Figure 8: Creep-rupture curves of (a) WF-filled PP composites containing FR and (b) CeFfilled PP composites containing FR. 


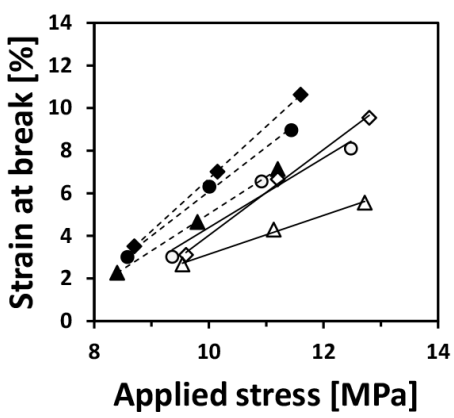

(a)

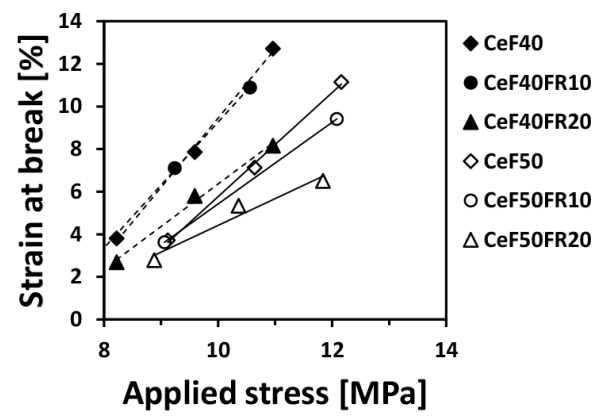

(b)

Figure 9: Relationship between the applied stress and strain at break: (a) WF-filled PP composites containing FR and (b) CeF-filled PP composites containing FR.

composites with FR (20 wt \%) and for biofiller (40 wt \%)-filled PP composites. Both the creep-rupture life and the strain at break decreased as the FR content increased.

To understand in detail how FR addition influences creep properties, the fracture morphology was observed through SEM, as shown in Fig. 10. Figure 10a shows the fracture surface of the WF50FR20 sample, and Fig. 10b shows the fracture surface of the CeF50FR20 sample. In the case of WF50FR20, the WF could not be observed due to its good compatibility with the PP. However, many large APP particles (circles) could be confirmed on the fracture surface. Since the APP particles were not wrapped by PP, the compatibility between APP and PP could have been weak, and the fracture may have been caused by large APP particles. Additionally, in the case of CeF50FR20, the pull-out of CeF and large particles of APP and the presence of large spherical holes were observed. Thus, the weak bonding properties between APP/PP and CeF/PP promoted creep deformation. To prevent the deterioration of the mechanical properties, the surface coating of APP with 3-(methylacryloxyl) propyltrimethoxy silane treatment [18] and beta-cyclodextrin through in situ polymerization [20] are effective solutions to improve the compatibility of PP and APP. This idea is based on the organic modification of the APP surface. However, these methods are limited to static tensile or bending properties. In this study, we found that APP addition significantly decreased the creep-rupture life. Thus, the effectiveness of the surface treatment of APP should be considered for the long-term creep properties to improve the reliability of the composites.

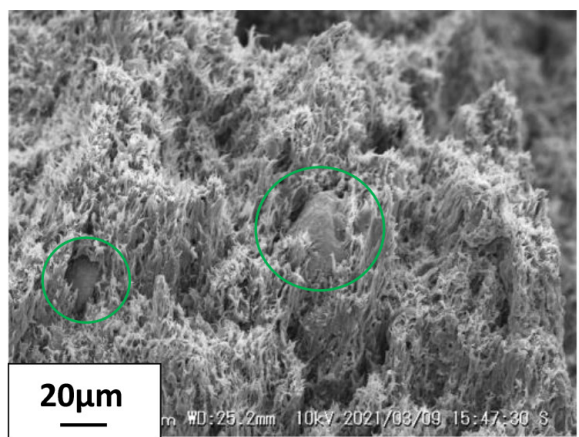

(a)

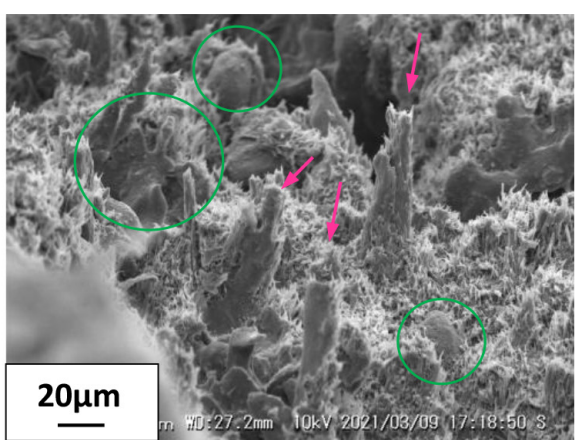

(b)

Figure 10: The creep fracture surface: (a) WF50FR20 and (b) CeF50FR20 (under stress of $60 \%$ of the tensile strength). 


\section{CONCLUSIONS}

In this study, we investigated the influence of the biofiller type (wood flour and cellulose filler), biofiller content and fire retardant (APP) content on the creep properties at $80{ }^{\circ} \mathrm{C}$. The creep strain curve in the linear viscoelastic region was successfully fitted by the Burgers model with six elements. In this study, we obtained the following conclusions:

1. The addition of biofillers restricted creep deformation with increasing biofiller content. Thus, the creep-rupture life of PP was notably improved. However, the creep-rupture life was longer with WF, a lignocellulosic filler, than with $\mathrm{CeF}$, a cellulosic filler, even though both fillers had nearly the same particle diameters and aspect ratios.

2. Higher contents of FR (APP) could decrease the instantaneous strain. However, the creep rate at steady state increased with APP addition. Furthermore, APP addition decreased the creep-rupture life and strain at break due to the weak compatibility between APP and PP.

\section{ACKNOWLEDGEMENTS}

This work was conducted as a part of the demonstration project for plastics resource circulation system for decarbonized society (FY2020) commissioned by MOEJ (Ministry of Environment, Government of Japan). We gratefully acknowledge MOEJ and the Research and Development Center for Advanced Composite Materials (RDCCM) of Doshisha University, and we thank Toclas Corporation for providing wood flour, cellulose filler and injection-moulded composite specimens for the creep test.

\section{REFERENCES}

[1] Jubinville, D., Esmizadeh, E., Saikrishnan, S., Tzoganakis, C. \& Mekonnen, T., A comprehensive review of global production and recycling methods of polyolefin (PO) based products and their post-recycling applications. Sustainable Materials and Technologies, 25, e00188, 2020. https://doi.org/10.1016/j.susmat.2020.e00188

[2] Sauter, D.W., Taoufik, M. \& Boisson, C., Polyolefins, a success story. Polymers, 9(6), p. 185, 2017. https://doi.org/10.3390/polym9060185

[3] Ares, A., Bouza, R., Pardo, S.G., Abad, M.J. \& Barral, L., Rheological, mechanical and thermal behaviour of wood polymer composites based on recycled polypropylene. Journal of Polymers and the Environment, 18, pp. 318-325, 2010. https://doi. org/10.1007/s10924-010-0208-x

[4] van den Oever, M. \& Molenveld, K., Creep deflection of wood polymer composite profiles at demanding conditions. Case Studies in Construction Materials, 10, e00224, 2019. https://doi.org/10.1016/j.cscm.2019.e00224

[5] Takemura, K., Effect of water absorption on static and creep properties for jute fiber reinforced composite. WIT Transactions on the Built Environment, 76, pp. 383-389, 2004.

[6] Park, B.-D. \& Balatinecz, J.J., Short term flexural creep behavior of wood-fiber/polypropylene composites. Polymer Composites, 19(4), pp. 377-382, 1998. https://doi. org/10.1002/pc.10111

[7] Kazemi-Najafi, S., Nikray, S.J. \& Ebrahimi, G., A comparison study on creep behavior of wood-plastic composite, solid wood, and polypropylene. Journal of Composite Materials, 46(7), pp. 801-808, 2012. https://doi.org/10.1177/0021998311410499 
[8] Lee, S.-Y., Yang, H.-S., Kim, H.-J., Jeong, C.-S., Lim, B.-S. \& Lee, J.-N., Creep behavior and manufacturing parameters of wood flour filled polypropylene composites, Composite Structures, 65(3-4), pp. 459-469, 2004. https://doi.org/10.1016/j.compstruct.2003.12.007

[9] Chandekar, H., Waigaonkar, S. \& Chaudhari, V., Effect of chemical treatment on creeprecovery behavior of jute-polypropylene composites. Proceedings of the Institution of Mechanical Engineers, Part L: Journal of Materials: Design and Applications, 235(2), pp. 329-340, 2021. https://doi.org/10.1177/1464420720963344

[10] Takemura, K., Takada, Y. \& Katogi, H., Effect of treatment using silane coupling agent on creep properties of jute fiber reinforced composites. WIT Transactions on the Built Environment, 124, pp. 417-424, 2012.

[11] Hung, K.-C., Wu, T.-L., Chen, Y.-L. \& Wu, J.-H., Assessing the effect of wood acetylation on mechanical properties and extended creep behavior of wood/recycled-polypropylene composites. Construction and Building Materials, 108, pp. 139-145, 2016. https://doi.org/10.1016/j.conbuildmat.2016.01.039

[12] Yadav, S. \& Yusoh, K., Sub-surface mechanical properties and sub-surface creep behavior of wood-plastic composites reinforced by organoclay. Science and Engineering of Composite Materials, 26(1), pp. 114-121, 2019. https://doi.org/10.1515/secm-20160291

[13] Nuñez, A.J., Marcovich, N.E. \& Aranguren, M.I., Analysis of the creep behavior of polypropylene-woodflour composites. Polymer Engineering \& Science, 44(8), pp. 1594-1603, 2004. https://doi.org/10.1002/pen.20157

[14] Yang, T.C., Chien, Y.C., Wu, T.L., Hung, K. C. \& Wu, J. H., Effects of heat-treated wood particles on the physico-mechanical properties and extended creep behavior of wood/ recycled-HDPE composites using the time-temperature superposition principle. Materials (Basel, Switzerland), 10(4), p. 365, 2017. https://doi.org/10.3390/ma10040365

[15] Yang, T.-C., Wu, T.-L., Hung, K.-C., Chen, Y.-L. \& Wu, J.-H., Mechanical properties and extended creep behavior of bamboo fiber reinforced recycled poly(lactic acid) composites using the time-temperature superposition principle. Construction and Building Materials, 93, pp. 558-563, 2015. https://doi.org/10.1016/j.conbuildmat.2015.06.038

[16] Arao, Y., Nakamura, S., Tomita, Y., Takakuwa, K. Umemura, T. \& Tanaka, T., Improvement on fire retardancy of wood flour/polypropylene composites using various fire retardants. Polymer Degradation and Stability, 100, pp. 79-85, 2014. https://doi. org/10.1016/j.polymdegradstab.2013.12.022

[17] Dou, Y., Guo, B., Guan, D., Shi, L., Yao, W. \& Zhang, W., The flame retardancy and mechanical properties of jute/polypropylene composites enhanced by ammonium polyphosphate/polypropylene powder. Journal of Applied Polymer Science, 133, p. 43889, 2016. https://doi.org/10.1002/app.43889

[18] Zhou, L., Guo, C. \& Li, L., Influence of ammonium polyphosphate modified with 3-(methylacryloxyl) propyltrimethoxy silane on mechanical and thermal properties of wood flour-polypropylene composites. Journal of Applied Polymer Science, 122, pp. 849-855, 2011. https://doi.org/10.1002/app.34069

[19] Wang, W., Zhang, S., Wang, F., Yan, Y., Li, J. \& Zhang, W., Effect of microencapsulated ammonium polyphosphate on flame retardancy and mechanical properties of wood flour/polypropylene composites. Polymer Composites, 37, pp. 666-673, 2016. https:// doi.org/10.1002/pc.23223 
[20] Wang, W., Peng, Y., Chen, H., Gao, Q., Li, J. \& Zhang, W., Surface microencapsulated ammonium polyphosphate with beta-cyclodextrin and its application in wood-flour/ polypropylene composites. Polymer Composites, 38, pp. 2312-2320, 2017. https://doi. org/10.1002/pc.23813

[21] Bakar, M.B.A., Ishak, Z.A.M., Taib, R.M., Rozman, H.D. \& Jani, S.M., Flammability and mechanical properties of wood flour-filled polypropylene composites. Journal of Applied Polymer Science, 116, pp. 2714-2722, 2010.

[22] Matsumoto, K., Tanaka, T., Sasada, M., Sano, N. \& Masuyama, K., A mechanism for fire retardancy realized by a combination of biofillers and ammonium polyphosphate in various polymer systems. Cellulose, 2021. https://doi.org/10.1007/s10570-021-03747-4

[23] Fiebig, J., Gahleitner, M., Paulik, C. \& Wolfschwenger, J., Ageing of polypropylene: processes and consequences. Polymer Testing, 18(4), pp. 257-266, 1999. https://doi. org/10.1016/s0142-9418(98)00023-3

[24] Faraz, M., Besseling, N., Korobko, A. \& Picken, S., Characterization and modeling of creep behavior of a thermoset nanocomposite. Polymer Composites, 36(2), pp. 322-329, 2015. https://doi.org/10.1002/pc.22946

[25] Gadioli, R., Morais, J.A., Waldman, W.R. \& De Paoli, M.A. The role of lignin in polypropylene composites with semi-bleached cellulose fibers: Mechanical properties and its activity as antioxidant. Polymer Degradation and Stability, 108, pp. 23-34, 2014. https://doi.org/10.1016/j.polymdegradstab.2014.06.005 